\title{
Prosodic Pointing in inferential comprehension: the application of Relevance Theory to L2 listening instruction
}

Pauline Madella is currently completing a $\mathrm{PhD}$ of Brighton. She holds an M.A. in English Language Teaching and has extensive experience teaching English to Chinese LI speakers. Her research explores the use and interpretation of ostensive non-verba communication and in particular their role in cueing speaker intentions. Her doctoral work focuses on how exposure to prosodic pointing in $L 2$ pragmatics instruction can enhance relevance-based pragmatic competence in Chinese hearers of L2 English. http://orcid.org/0000-0001-5847-4274 E-mail: P.Madella@brighton.ac.uk

Jesús Romero-Trillo is Full Professor in Pragmatics at the Department of English Philology (Universida Autónoma de Madrid). He obtained an MSc in Applied Linguistics at the University of Edinburgh, as a Stevenson Scholar (1990) and finished his PhD at the Universidad Complutense de Madrid (1994). He specialises in Applied Linguistics with specific emphasis on the theory and application of corpus English and cognition and the study of social conflict $\mathrm{He}$ i is the Editorin-Chief of the journal Corpus Pragmatics (Springer). http://orcid.org/0000-0002-8295-3387 E-mail: jesus.romero@protonmail.com

Recebido em: 14/05/2019. Publicado em: 27/12/2019.

Endereço:

Pamella Madella

Mithras House

Lewes Road

Brighton

BN2 4AT

Jesus Romero-Trillo

(T)

Campus de Cantoblanco, UAM, 28049 Madrid
Apontamento prosódico na compreensão inferencial: a aplicação da Teoria da Relevância à instrução auditiva L2

Pauline Madella ${ }^{12}$

University of Brighton, Hastings, Inglaterra

Jesús Romero-Trillo ${ }^{34}$

Universidad Autónoma de Madrid, Madrid, Espanha

\section{ABSTRACT}

The interface between pragmatics and prosody has been shown to be significant in intercultural communication (RIESCO BERNIER; ROMERO-TRILLO, 2008; ROMERO-TRILLO, 2002, 2012, 2015, 2019). In this paper, we re-evaluate the pragmatics-prosody interface on the grounds that prosody is seldom interpreted independently from accompanying gesture, facial modification and head movement. To enhance L2 hearers' pragmatic competence, or what we define as attentional and inferential abilities, we introduce prosodic pointing as an ostensive phenomenon inclusive of both vocal and visual paralinguistic features used synchronously to communicate and interpret one's intentions. We believe that the way relevance mechanisms (SPERBER; WILSON, 1986; WHARTON, 2014) focus the hearer on the speaker's ostensive nonverbal behaviours, for him to use them as cues to speaker meaning, can be exploited in L2 listening instruction that aims to develop epistemic vigilance (SPERBER 1994; PADILLA CRUZ, 2013) and pragmatic competence in Chinese hearers of L2 English. In English, you can show disagreement by saying 'Yes, he \was'. In Chinese, however, 'yes' always means agreement. Chinese speakers typically disagree by saying 'No, he was', thus potentially causing misunderstanding. We investigate how introducing prosodic pointing to Chinese L2 learners can help in fine-tuning their epistemic vigilance in L2 English through an intervention study involving input and immediate recall sessions. The results show (i) evidence of Chinese interpreters of L2 English fine-tuning their epistemic vigilance and, as result, the important role of prosodic pointing in enhancing their pragmatic competence, and (ii) the need for further relevance-based L2 instructional studies focused on enhancing inferential and interpretive competence in hearers of L2 English. KEYWORDS: Prosodic pointing; Pragmatic competence; Epistemic vigilance; Relevance theory; L2 listening instruction

2 This paper is based on the following presentation: The pragmatics of prosodic pointing: the application of relevance theory to L2 prosody and gesture awareness. INPRA 2018. University of Cyprus.

This work was supported by the Ministerio de Economía y Competitividad (Spain) under Grant FFI2016-75160-R. 


\section{RESUMO $^{5}$}

A interface entre pragmática e prosódia tem se mostrado significativa em comunicação intercultural (RIESCO BERNIER; ROMERO-TRILLO, 2008; ROMERO-TRILLO, 2002, 2012, 2015, 2019). Neste artigo, nós reavaliamos a interface pragmática-prosódica assumindo que a prosódia é raramente interpretada de maneira independente de gestos, modificações faciais e movimentos de cabeça. A fim de aprimorar a competência pragmática do ouvinte em L2, ou o que definimos como habilidades inferencial e de atenção, introduzimos o conceito de indicação gestual-prosódica (prosodic pointing) como uma ferramenta baseada na relevância que inclui características tanto segmentais como paralinguísticas, usadas sincronizadamente para comunicar a intenção do falante. Acreditamos que a maneira como mecanismos de relevância (SPERBER; WILSON, 1986, WHARTON, 2014) fazem o ouvinte focar em comportamentos ostensivos não-verbais - a fim de que ele as use como pistas para o significado do falante - pode informar instruções de compreensão oral em L2 que busquem desenvolver a competência pragmática e a vigilância epistêmica (PADILLA CRUZ, 2013) em falantes chineses de inglês como L2. Em inglês, você pode mostrar discordância ao dizer 'sim, ele $\backslash$ foi'. Em chinês, no entanto, 'sim' sempre significa concordância. Falantes chineses normalmente expressam discordância ao dizer 'Não, ele foi', o que potencialmente pode causar um mal-entendido. Nós investigamos como a introdução de 'instruções prosódicas' para chineses aprendizes de L2 pode aprimorar a competência pragmática e a vigilância epistêmica através de um estudo de intervenção com uma combinação de metodologias que envolvem testes de recepção, testes de compreensão oral e testes de recordação. Os estudos mostram (i) a necessidade de instruções que coloquem o aprendiz de L2 em um papel direto de ouvinte a fim de que sua atenção selecione as pistas ostensivas do falante e as use em seu processo de interpretação e (ii) a importância de melhorar as instruções de compreensão inferencial partindo de estudos de L2 baseados na relevância.

PALAVRAS-CHAVE: Prosodic Pointing; Competência Pragmática; Vigilância Epistêmica; Teoria da Relevância; Instruções de Compreensão Oral em L2.

\section{Introduction}

$\mathrm{T}$ he 'yes' and 'no' concepts, whether word- or gesture-based, are often seen as universal features, while they can in fact be a cause of intercultural miscommunication. For example, in Greek, 'neh', which typically sounds like 'nah' to an English speaker's ear, means 'yes'. In India, the quick head wobble, commonly used to mean 'yes' or 'alright', can be a source of much confusion. In

The authors would like to greatly thank Dr Claudia Strey for translating the abstract. other cases, the confusion may come from the dual meaning of the same gesture, i.e., in English, a nod can also show disagreement and it is only through prosody and other paralinguistic features that one can disambiguate between a 'yes' that means agreement and one that means disagreement. This dual meaning is particularly relevant to Chinese learners of English, as in Chinese, 'yes' or a nod always means agreement and 'no' or a head shake disagreement. By way of illustration, let us imagine that an L1 speaker of English asks: 'David isn't in this morning, then?', to what a Chinese learner of L2 English responds: 'Yes' and nod at the same time. The L1 speaker is likely to infer disagreement: 'Yes, he $\backslash$ is in', while the L2 speaker means agreement: 'Yes (you are right), he isn't'. To answer positively to the question asked, the L2 speaker is expected to say: 'He isn't, no' possibly with a head shake. In Chinese, 'yes' and a nod agrees with what our interlocutor thinks, while in English, it refers to the action being described (HALLIDAY, 1967). We believe that the illustrated confusion between Chinese and English L1 speakers can have serious implications for L2 speakers' and hearers' performance and lead to pragmatic failure in intercultural communication.

The present paper focuses on the development of pragmatic competence in Chinese L2 hearers, which is specifically related to the development of their L2 epistemic vigilance (SPERBER et al., 2010; PADILLA CRUZ, 2013, 2016; IFANTIDOU, 2016). As Padilla Cruz (2013, p. 121) states, overreliance on linguistic input (i.e. bottom-up processing) and under reliance on suprasegmental and paralinguistic phenomena, generally used in top-down processing, feature among typical pragmatic problems in L2 learners, characterised by 'less sophisticated interpretive abilities than those of natives.' We depart from the view that it is through learned attention to prosody and other paralinguistic features that L2 learners can disambiguate between a 'yes' that agrees and one that disagrees. In the second section of this paper, we show that instruction that aims at developing L2 hearers' attentional and inferential abilities (i.e. pragmatic competence) must be anchored in top-down mechanisms as described by inferential pragmatics so as to focus the L2 hearer's attention on the speaker's intentions and stress to them the importance of speaker's nonverbal communicative behaviours as a cue to meaning. In the third section, we highlight how relevance theory, and ostensive inferential communication 
mechanisms in particular, can be used in L2 listening instruction to develop L2 hearers' epistemic vigilance, i.e. the ability to critically reassess their interpretive reasoning by taking into account all, prosodic and gestural, ostensive communicative behaviours to work their way to the speaker's intended interpretation. In the fourth section, we offer our rationale for using prosodic pointing as an ostensive phenomenon and tool for testing and developing pragmatic competence in L2 hearers, and thereby refine the pragmatics-prosody interface. In the final section of the paper, our intervention study tests our hypothesis that exposure to prosodic pointing can help L2 Chinese hearers to disambiguate between a 'yes' or positive answer that agrees and a 'yes' or positive answer that disagrees, and develop their L2 epistemic vigilance as a result. Based on the convergence of both quantitative and qualitative results, we offer a discussion and directions for future research.

\section{Inferential pragmatics and top-down processing in $L 2$ comprehension}

Inferential pragmatics, introduced by Grice (1975), has only relatively recently been acknowledged as relevant to second language learners and teachers (ZUFFEREY, 2015). Inferential pragmatics as a discipline developed as a result of Grice's intuition that there is more to human communication than a simple process of coding and decoding. Rather it is a process involving the inferential recognition of the communicator's intentions. According to subsequent models of inferential pragmatics, utterance interpretation requires the hearer to search beyond the semantic meaning of the speaker's message in order to infer what it is that the speaker intends to communicate, referred to as speaker meaning or intended meaning. In the same way as inferential pragmatics is essential to understanding language use and communication, we believe that it is necessary to foster the kind of top-down processing that it involves in second language teaching. Pragmatic competence does not only come from the ability to decode input, but it requires the ability to read the speaker's intentions in producing it. Thus, we endorse the view that $\mathrm{L} 2$ pragmatic instruction must involve focusing second language learners' attention not only on the linguistic form of an utterance but also, and crucially, on the cues that typically act as pointers to the speaker's intentions. Following Gricean and post-Gricean pragmatic theories, we see the speaker as the initiator of a communicative act and the social-cognitive mechanisms that the act of communication triggers as being of pivotal significance for $\mathrm{L} 2$ comprehension instruction. This implies that the social dimension of the cognitive mechanisms underlying language processing and language acquisition, and the 'joint activity' between hearer and speaker (HÖMKE; HOLLER; LEVINSON, 2018, p. 1) requires adopting a less traditional way of thinking the language-meaning relationship. The view endorsed in this paper is in line with the thesis put forward by Macnamara (1972) according to which infants do not in fact use language as a cue to meaning, but rather use meaning as a cue to language. Although Macnamara's thesis (1972) was meant to shed light on first word acquisition, we believe that this meaning-comes-first logic is relevant to second language listeners and to the development of their pragmatic competence. The bottom line of Macnamara's thesis is that the linguistic input should not be thought of as the starting point. Learners relying on the linguistic as a starting point and cue to meaning are bound to fail in attributing the right intentions to the speaker and in recovering the intended interpretation. Macnamara's thesis and inferential pragmatics share the underpinning idea that utterance interpretation is not just about understanding what the words mean but what the speaker intends to communicate in using these words (GRICE, 1975; SPERBER; WILSON, 1986, WHARTON, 2014). We believe that L2 pragmatics instruction should be anchored in the idea that the speaker herself and her intentions is the starting point and the guiding line of utterance interpretation, because, ultimately, the point is to recover the utterer's meaning. These parallels between the topdown processes at work in lexical acquisition and those at work in inferential comprehension are further highlighted by Wharton (2014) who sees lexical acquisition as an exercise of a pragmatic ability. He draws on Bloom's claim (2001a; 2001b) that children's sensitivity to the mental states of others causes them to work out what it is that communicators intend to refer to when they use this or that word, thereby playing a central role in the process of lexical acquisition. Children, therefore, from an early age, (learn to) understand words with reference to their user's intentions and, as a result, successfully attribute intended meanings to words. If the processes involved in lexical 
development are typically used in adult comprehension, then we believe that they are likely to inform L2 comprehension instruction.

The skills implicated in the way adult speakers use and understand them are the same skills that Bloom sees as crucial to the way children acquire the meanings of words. Just as children are required to attribute intentions and interpret natural cues in order to acquire word meanings, so adult hearers must do so in order to interpret successfully the words they hear. (WHARTON, 2014, p. 479)

Comprehension inevitably involves a focus of the hearer's attention on the speaker's intentions, and the use of what Wharton (2014, p. 479) calls the speaker's 'natural cues' as interpretive cues to carry out top-down processing and successfully interpret intended meaning. The essential idea is that what focuses the hearer's attention on the speaker's intentions are the speaker's natural, ostensive, nonverbal behaviours that inevitably accompany speech (e.g. tone of voice, gesture, facial expression, head movement), often known as paralinguistic phenomena (WHARTON, 2014, 2016). They provide cues to the intended meaning of the words the speaker has chosen to use. If these are absent, the L2 hearer is left with impoverished input which, in cases that require the use of more sophisticated strategies, will not be sufficient to recover the intended interpretation. A lack of awareness of the role of paralinguistic phenomena as guiding cues to the intended interpretation can explain the over reliance on the linguistic input and the tendency for bottom-up processing in L2 learners. It can also explain why learners may not critically assess their interpretation and use the most accessible, linguistic interpretation as the intended one. This may also cause and explain the hearer's detachment from the speaker and reliance on language as independent of its user, which, as Padilla Cruz (2013) suggests, may end up in the hearer failing to read their interlocutor's mind. We argue that attention to the speaker's ostensive communicative behaviours should be learned and used in L2 pragmatic comprehension instruction to encourage top-down processing, less reliance on linguistic input and greater awareness of the role and relevance of nonverbal cues in L2/ intercultural communication. In our opinion, L2 instruction should stress the important role of speakers in cueing their communicative intentions to assist the hearer in his recovery of the intended meaning. It should also highlight the complexity of speaker's intentions requiring the hearer to combine and integrate multiple cues in a single interpretation. Therefore, we believe that relevance theory's model of ostensive inferential communication can serve as a pedagogical guideline for L2 listening comprehension instruction.

\section{Relevance theory, listening comprehension and pragmatic competence}

Relevance theory, as a theory of communication, has its foundations in cognitive science and psychology (SPERBER; WILSON, 1986). While it focuses primarily on the part that does the interpretive work, the comprehension procedure as developed by Sperber and Wilson (1986) also recognises an important role for the speaker (WHARTON, 2008). In fact, the universal cognitive mechanisms underlying comprehension which the relevance comprehension procedure exploits are intrinsically social, as the two principles of relevance below illustrate.

- Cognitive principle: Because human cognition tends to be geared towards the maximisation of relevance, attention tends to pick out the most relevant stimuli, pointing the hearer towards the speaker's intended conclusion.

- Communicative principle: 'Knowing your tendency to pick out the most relevant inputs and process them so as to maximize their relevance, I may be able to produce a stimulus which is likely to attract your attention, activate an appropriate set of contextual assumptions and point you toward an intended conclusion.' (SPERBER; WILSON, 2004, p. 9).

This balance between the active roles of hearer and speaker is clearly reflected in relevance theory's two principles. The potential for pedagogical support is to be found specifically in the relation between hearer and speaker, between speaker's ostensive behaviour and hearer's inferential work. What is crucial to instructed listening comprehension, and what the present work exploits is precisely that 'inferential communication is intrinsically social, not just because 
it is a form of interaction, but also, less trivially, because it exploits and enlarges the scope of basic forms of social cognition' (SPERBER; WILSON, 1997, p. 2).

Relevance mechanisms and the ostensive-inferential processes that they entail exploit basic forms of social cognition. For instance, it exploits the sharing of attentional focus between the speaker and the hearer, also commonly called joint (or shared) attention mechanism (MUNDY; NEWELL, 2007). As work in social cognition suggests, early developed cognitive mechanisms such as joint attention do imply a social partner and someone to share one's focus of attention with. According to relevance theory, the speaker shares their focus of attention as a means of guiding the hearer to interpret goal-oriented behaviour. This shows that what relevance theory assumes is that one goal of cognition is to be social. We follow Sperber and Wilson on this assumption as we believe that the social cognition mechanisms underlying the relevance theoretic comprehension procedure bears important implications for L2 instructional inferential abilities. We contend that for L2 hearers to make inferences they need exposure to ostensive communicative behaviours, which will activate social cognition mechanisms focusing their attention and pointing it towards speaker meaning. The production (by the speaker) of a stimulus that is likely to attract attention and the tendency (of the hearer) to pick out a stimulus that is perceived as ostensive and to believe that what has been brought to their attention is likely to yield positive cognitive effects is the underlying idea behind what Sperber and Wilson call 'ostensive inferential communication', and, we propose, the underlying idea behind L2 pragmatics instruction. According to the ostensive inferential communication's model, unless the hearer attends to the speaker's ostensive behaviour focusing him on her intentions, the hearer will fail to notice relevant input and, as a result, to recover the intended meaning.

The use of relevance principles in understanding second language processing (JODLOWIEC, 2010; ZUFFEREY, 2015) shows that relevance mechanisms are not language specific. However, although they are universal cognitive mechanisms, relevance mechanisms are not sufficient for L2 hearers to become pragmatically competent in their second language. One reason for this is that as part of the attentional and inferential abilities that underpin the relevance comprehension procedure, there is what Sperber et al. call 'epistemic vigilance' (2010). Alongside developing mindreading and relevance-based comprehension mechanisms, the language user exploits dedicated cognitive mechanisms for epistemic vigilance:
'A disposition to be vigilant is likely to have evolved biologically alongside the ability to communicate in the way that humans do.' (SPERBER et al., 2010).

Such disposition makes hearers take a critical stance towards communicated information and towards their own interpretive performance. They may end up rejecting their first choice on the basis that there is a better alternative. Yet this critical stance and testing of interpretations that epistemic vigilance entails is only possible if the hearer can access the alternative(s). As Sperber (1994) describes, children become capable of adjusting their interpretations at around the same time as they develop first-order theory of mind mechanisms and more generally social cognition. These theory of mind mechanisms, that children usually rely on and build on to become vigilant are the so-called shared attention mechanisms (SPERBER, 1994). The available input that L2 learners have for inferential processes can be described as impoverished, due to restricted access to the speaker's natural cues (i.e. paralinguistic phenomena). However, L2 learners are capable of relying on the shared attention mechanisms required to connect with their interlocutor and have their attention focused on reading their interlocutor's mind. On these grounds, we believe that L2 comprehension instruction needs to capitalise on the predisposition of L2 learners to engage with a social partner, in order to focus their attention on their interlocutors' intentions. These mechanisms focusing the hearer's attention on the speaker's intentions are typically triggered by ostensive non-verbal communicative behaviours. This is precisely why we believe that L2 instruction should focus on improving L2 hearers' access to natural ostensive cues, through learned or refocused attention, for them to develop more sophisticated processing strategies as vigilant L2 hearers. The development of more sophisticated interpretive strategies by improved reading of contextual cues can be done through awareness-raising instruction that aims to expose them to paralinguistic cues that they may otherwise miss or misuse, leading them not to accept the first, most obvious interpretation, but to push their boundaries so as to take more into account and allow more to be seen as presumptions of relevance. Based on the relevance theoretic comprehension procedure (WILSON; SPERBER, 2002, p. 13), we see that an interpreter would typically: 
(a) Follow a path of least effort in computing cognitive effects: Test interpretive hypotheses (disambiguations, reference resolutions, implicatures, etc.) in order of accessibility;

(b) Stop when their expectations of relevance are satisfied.

Following the above description and in the simplest case, it is expected that an interpreter would follow a path of least effort in interpreting an utterance and that he would stop at the first interpretation that he found relevant enough (WHARTON, 2014). The L2 interpreter's selection of one 'relevant enough' interpretation, however, may not be a result of having discarded hypotheses that were less relevant, but a result of their restricted access to these interpretive hypotheses (PADILLA CRUZ, 2013; WHARTON, 2014). Failing to pay attention to relevant input may restrict their access to and testing of interpretive hypotheses. By stopping at the first, most accessible interpretation they may misread intentions or not comprehend the implications of linguistic input. As relevance is a matter of degree, it is assessed in terms of costs and benefits, where cost refers to processing effort and is to be minimised, while benefit refers to positive cognitive effects and are to be maximised. Improved access to costly suprasegmental and paralinguistic cues and learned recognition of these cues as presumptions of relevance will encourage L2 learners not to accept the first most accessible interpretation as relevant enough and put in more processing effort to reach the intended one.

Let us apply the comprehension procedure to the understanding of a 'yes' answer expressing disagreement by Chinese listeners of L2 English. Let us consider that an L2 interpreter hears and sees his interlocutor utter (1):

(1) Yes, Karl \was at the party. Didn't you see him? (frown - negative facial expression, as if surprised or questioning)

In (1) the linguistically coded positive verb form 'was' may first guide the L2 listener towards a positive interpretation. If the hearer accesses the frown and the negative look on the speaker's face, this may activate epistemic vigilance mechanisms leading the interpreter to reassess his first interpretation. The reading of contrastive stress applied to 'was' (i.e. \was) can help him make sense of the frown and negative facial expression and point him towards the conclusion that the speaker is seeking to make the positive verb form salient to show that he disagrees with the hearer, who thinks that Karl was not at the party. What this shows is that attention to both prosodic and gestural cues can help to discriminate a 'yes' that agrees from one that disagrees. An L1 interpreter will have access to and will read these prosodic and gestural cues together. In L2 comprehension, however, it may not be as simple. Thus, improved access and alertness to these cues can help L2 hearers to go beyond linguistic input and understand that there is more to the speaker's input than what is linguistically encoded (e.g. the disagreement expressed by the speaker). It is important to note that the use of contrastive stress alone is not enough evidence of the speaker's intended meaning. In production, contrastive stress is seldom used without bodily or facial modifications being activated simultaneously, and in comprehension, contrastive stress is never interpreted in isolation. In relevance theoretic terms, contrastive stress and a pointing gesture are analysed under the same lines: as ostensive communicative behaviours that create expectations of relevance and are used as natural highlighting devices (SCOTT, 2017). This supports us in looking specifically at contrastive stress as it is typically produced and processed together with co-pointing gestures, head movements and facial expressions, all being ostensive paralinguistic communicative behaviours to be picked out and used in the inferential process.

We thereby expand the pragmatics-prosody interface into a phenomenon that includes all paralanguage; this is what we call prosodic pointing. Prosodic pointing involves not only contrastive stress, but also the facial modifications (i.e. frown), head movement (i.e. nod) and co-pointing gestures that contrastive stress naturally and typically patterns with in English. We hypothesise that giving a central role to multimodal cues - as opposed to prosodic cues only, can achieve the following:

(1) Focus Chinese hearers of L2 English's attention on speaker's intentions;

(2) Help listeners to develop more sophisticated, top-down interpretive strategies (i.e. as part of developing L2 epistemic vigilance), and in particular

(3) Help learners to discriminate a 'yes' answer that means 'yes' from a 'yes' answer that means 'no'. By stopping at the first, most accessible interpretation they may misread intentions or not comprehend the implications of linguistic input. 
To achieve these objectives, we will focus on the interpretation of prosodic pointing applied together with verb forms for expressing 'yes' or 'no' answers. We argue that exposure to prosodic pointing rather than contrastive stress alone can trigger ostensive-inferential mechanisms, focus L2 hearers' attention on their interlocutor's intentions and encourage them to carry out top-down processing.

\section{The study 6}

The interventional study reported in this paper is part of a broader research project $^{7}$ that explores whether and how Chinese hearers of L2 English's pragmatic competence can be enhanced via exposure to prosodic pointing. The project as a whole included a pre- and post-test design and betweengroup comparison to assess the effectiveness of the intervention reported in the present paper. Statistical evidence shed light on the effectiveness of the intervention in enhancing the experimental group's pragmatic competence. The present paper focuses on the intervention itself and, as a result, on the experimental group only, because its aim is to investigate whether exposure to prosodic pointing, as opposed to contrastive stress alone, raised Chinese hearers of L2 English's alertness to paralinguistic cues and helped to attune their epistemic vigilance to the peculiarities of the L2 (PADILLA CRUZ 2013).

\subsection{Research design and methods}

\subsubsection{The participants}

The participants were enrolled on a 12-week summer English course at the University of Surrey, UK. 15 participants were recruited. They all shared the same variables: they were Mandarin Chinese native speakers, learners of English, at pre-masters' level, with a 5.5-6.5 IELTS test score and without prior experience living in the UK.

6 Ethics approval was issued by the College Research Ethics Committee for the College of Arts and Humanities at the University of Brighton on 24 May 2017. Protocol number of approval: AHCREC 17-11.

MADELLA, Pauline. Prosodic pointing: from pragmatic awareness to pragmatic competence in Chinese hearers of L2 English, forthcoming unpublished doctoral thesis, University of Brighton, 2020.

\subsubsection{Procedure and timeframe}

The participants were exposed individually to a dialogue involving instances of prosodic pointing (i.e. prosodic and gestural pointing with facial expression and head movement) used on verb forms to express agreement, disagreement or 'yes' or 'no' answers. At Level 1, the participants had access to the audio-only version of the dialogue, while at Level 2, they were exposed to the audio-andvideo version of the dialogue. Level 1 input and recall sessions were organised in the first two weeks of July 2017, while Level 2 individual input and recall sessions were arranged in the last two weeks of July 2017.

\subsubsection{The research design}

The rationale for using introspective methods is to be found in the benefits of using qualitative methods and of gathering qualitative data to explain or validate quantitative data, to explore surprising quantitative results and/or provide a more insightful and complete picture of the reality (CRESWELL; PLANO CLARK, 2006). In the present intervention, the comprehension test results were not meant to yield quantitative results as such, but they were used to compare the participants' test answers and their self-reported thought processes indicative of their interpretative route at both Level 1 and Level 2. The comprehension questions were primarily designed to provide a basis for the participants' interpretive processes. We used and compared comprehension test answers and qualitative descriptions of interpretive processes because we believe that there is more to inferential comprehension than comprehension. Evidence of the mental processes at play in interpreting intentions can complement, validate or contradict the comprehension test outcomes. We cannot access the participants' interpretive processes unless we access their thoughts while answering comprehension questions. The conclusion that they arrive at may or may not reflect the reasoning process they have gone through, and we are both interested in their (mis) understanding reflected by the quantitative results and the interpretive journey reflected by the qualitative data reported by participants, as both may be needed to assess the effectiveness of the proposed instruction.

Comparing between the amount and nature of interpretive reasoning reported by participants at Levels 1 and 2, will show whether access and exposure to all paralinguistic cues, as opposed to suprasegmental ones only, 
engages them in more sophisticated interpretive activities involving inferences of speakers' intentions and whether increased attention to ostensive nonverbal cues enhances their ability to use them in the inferential work.

\subsubsection{The research instrument and the skills tested}

The dialogue (attached in Appendix 1) was played twice both at Level 1 and Level 2. The participants were asked comprehension questions related to the three samples marked in bold in Appendix 1. More specifically, they were asked what Speaker 2 meant (e.g. 'yes', 'no', agreement) in uttering (2), (4) and (6), and why or how they knew (e.g. from Speaker 2's use of stress, face, frown). The latter question was meant to encourage the reporting of thought processes.

(1) Speaker 1: Shame Karl was not at the party.

\section{(2) Speaker 2: He \was at the party. Didn't you see him?}

Description of visual input and intended interpretation: Speaker 2 frowns and looks surprised. He disagrees with Speaker 1.

(3) Speaker 1: Is she trying to lose weight?

\section{(4) Speaker 2: She $\backslash$ was.}

Description of visual input and intended interpretation: Speaker 2 maintains eye contact with Speaker 1; his face shows that this is not the whole story. The use of a fall-rise ('She $\backslash$ / was') also indicates that Speaker 2's answer means more than 'she is no longer trying'.

(5) Speaker 1: Jay wasn't there then?

(6) Speaker 2: He \wasn't \no.

Description of visual input and intended interpretation: Speaker 2 shakes his head as a sign of agreement. His face agrees. Speaker 2 agrees with Speaker 1.

All three samples present contradiction between their linguistic form (positive or negative) and the visual cues available at Level 2. They also all involve prosodic emphasis on a verb form, which, we suggest, can help participants to work out how the visual input is to be interpreted. What we intend to find using these three samples is evidence that, at Level 2, the participants can see that there is more to the speaker's meaning than what the linguistic input alone suggests, and that access to all paralinguistic cues (e.g. prosodic information, frowns, disagreeing face, maintained eye contact) can help them to go from a wrong or relevant enough interpretation at Level 1 to the optimally relevant or intended interpretation at Level 2. For example, the past tense in 'She $\backslash /$ was' may be seen as sufficient information to infer that 'she' is no longer trying to lose weight. This, however, is not the optimally relevant interpretation; it is a relevant enough interpretation. Speaker 2's prosodic and visual cues show that what he intends to communicate is that 'she' gave up, that there have been complications or that he is not supposed to tell.

\subsection{Analysis of Results}

\subsubsection{Data Analysis}

The participants' comprehension test answers were measured based on the participants' responses to the three test questions at Level 1 and Level 2. Based on a comparison between Level 1 and Level 2 results, four categories emerged: maximum score, improvement, no learning and negative learning as represented below.

Counting of right answers (I) and wrong answers (0)

- 1-1 = maximum score

- $0-1=$ improvement

- $0-0=$ no learning

- 1-0 = negative learning

Participants who obtained a 'maximum score' answered correctly to the test question at both Levels 1 and 2. They are said to have reached a maximum score at Level 1 and therefore cannot obtain a higher score at Level 2. They have at least reached a relevant enough interpretation at both Levels. However, we will see 
that the qualitative responses of the participants may contradict results that are quantitatively seen as being maximal, in that the qualitative responses may indicate further improvement. Respondents showing 'improvement' answered incorrectly at Level 1 and correctly at Level 2, showing progression and possibly use of ostensive visual cues. To be more specific, by 'improvement' we mean that the participants would go from providing a wrong answer at Level 1 to providing at least a relevant enough interpretation at Level 2 . The following example is based on sample 3 :

- He wasn't no = 'no' (Level 1) -> Yes, he wasn't (Level 2)

In the above example, participant (6) challenged their 'default' interpretation and L1-based assumption that 'wasn't' must mean 'no', but they did not go as far as reaching the intended interpretation at Level 2. Respondents showing 'no learning' answered incorrectly at both Levels and are therefore seen as showing no learning between Level 1 and Level 2. Respondents showing 'negative learning' answered correctly at Level 1 but incorrectly at Level 2. This is unexpected but could happen as a result of misusing and misinterpreting visual cues. All four categories need further investigation based on the respondents' qualitative answers, attached in Appendix 2.

Evidence of qualitative improvement would involve participants challenging their initial or 'default' interpretation and reaching the intended interpretation, or participants going from a relevant enough interpretation at Level 1 to the optimally relevant interpretation at Level 2. Qualitative improvement would also involve evidence of participants using the visual input available at Level 2 appropriately to infer Speaker 2's intended meaning.

\subsubsection{Results Analysis}

A first, general glance over the qualitative data, shows that the participants reported more data related to their interpretive thoughts at Level 2 compared to Level 1: 238 words were collected at Level 1 compared to 344 words at Level 2. Overall, Level 2 brings about more of an interpretation from the participants; it is not just about answering the question. More has been noticed, which may be due to the participants having visual access to interpretive clues and therefore more to talk about. It may also be due to the visual input giving the participants more to remember in the immediate recall. It does in any way show that these extra contextual clues tend to be picked out by their attention, but whether these are then used in the inferential path is what a closer look at the qualitative data and its convergence with the comprehension test results will seek to show. As well as the quantity of data, the quality of data varies from Level 1 to Level 2, with intention-oriented interpretations emerging, particularly from interpreting answer 3. For instance, participants (1), (10) and (14) provide intention-oriented interpretations: 'No', agrees with her', 'he thinks she's right', 'Yes, he agrees', which shows their ability to read Speaker 2's mind.

On the surface, a comparison of the participants' Level 1 and Level 2 test answers seems to offer surprising results suggesting that there is no additional benefit of having access to prosodic pointing rather than prosody alone on verb form.

\section{Fig. 1 Sample 1 results: Before and after integrating qualitative data}

\section{SAMPLE 1 RESULTS}

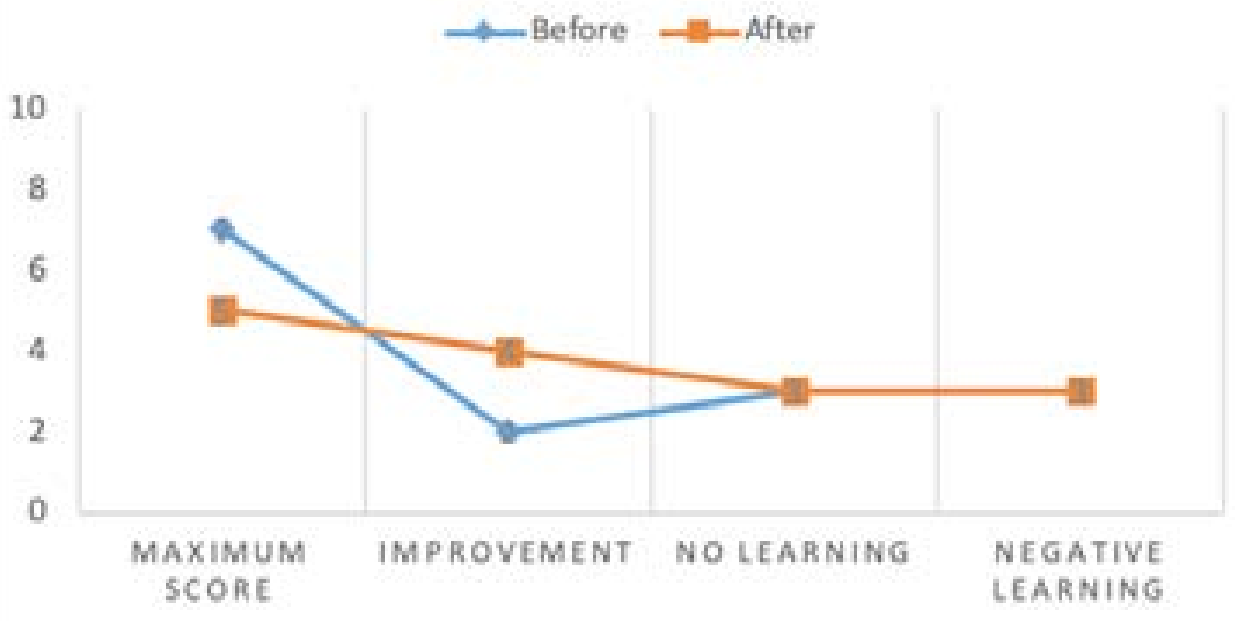

Fig. 1 represents the difference between what sample 1 comprehension test results suggest and what the results tell us about the participants' performance once the qualitative data has been integrated. As Fig. 1 shows, 
Sample 1 quantitative results report that $47 \%$ of the participants obtained a maximum score, $13 \%$ of them have improved and the rest of them report either no learning $(20 \%)$ or negative learning $(20 \%)$. What needs to be further investigated here is what is behind a 'maximum score' result: whether it means that the participants have got the right answer both times but have not got to the intended interpretation, or that their qualitative interpretation shows that they have reached the intended conclusion the second time. The qualitative data shows that three out of the seven 'maximum score' participants improved between Level 1 and Level 2 by reaching the intended interpretation at Level 2 (e.g. 'he looks surprised that she didn't see him' participant 1). None of them, however, reported to have understood that the speaker disagrees. Other 'maximum score' participants noticed more at Level 2 , including the speaker's head shake and the frown, but they did not go as far as using it in the inferential path. Out of the two participants reporting 'improvement', one did not provide evidence of their interpretation nor of them reaching the intended interpretation, while the second 'improvement' jumped from providing a wrong answer (at Level 1) to one that contains the closest reported interpretation to the intention to disagree (at Level 2): "he was - meaning 'no" (participant 12). The participants reporting 'no learning' and 'negative learning' have one thing in common, which is to have read the noticed contextual cues (i.e. speaker's face) wrong and misinterpreted the speaker's intentions. The 'no learning' participants typically used the 'face that says no' to consolidate (at Level 2) their wrong answer (at Level 1), while the 'negative learning' participants changed their originally right, positive answer for the wrong, negative answer based on the negative face of the Speaker 2.
Fig. 2 Sample 2 results: Before and after integrating qualitative data

\section{SAMPLE 2 RESULTS}

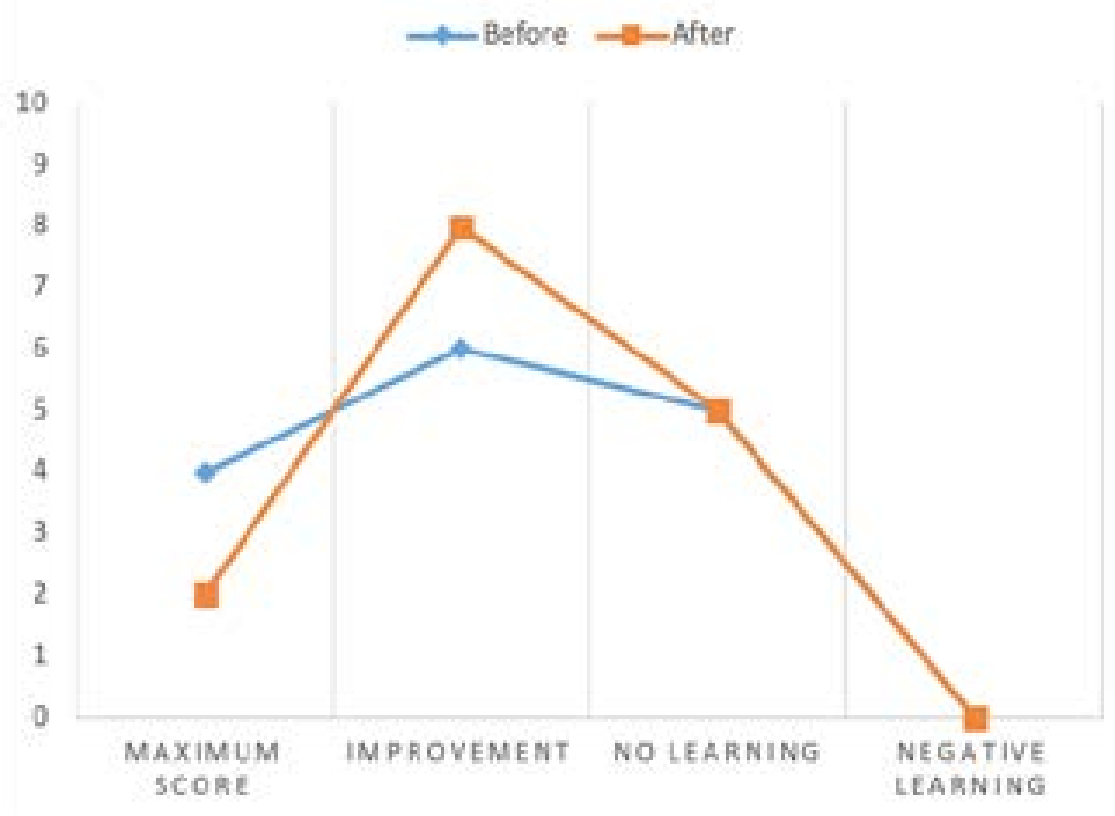

Fig. 2 represents the difference between what sample 2 comprehension test results suggest and what the results tell us about the participants' performance once the qualitative data has been integrated. As Fig. 2 illustrates, Sample 2 results report $40 \%$ of 'improvement', $33 \%$ of 'no learning' and the rest of the participants $(27 \%)$ having obtained a maximum score. Among the 'no learning' responses, three show similar causes as the ones identified in Sample 1 responses, that is the participants' misuse of the speaker's face to consolidate a wrong interpretation, and the noticing of the speaker's face or head shake without using it to challenge their initial interpretation. The other two 'no learning' responses seem to confirm the pragmatic problems identified as typical of L2 learners by Padilla Cruz (2013), such as overreliance on the conceptual meaning 
of 'was' as a positive answer and the difficulty or reluctance to challenge L1established rules. The past tense 'was' shows to have also contributed to half of the improved responses $(20 \%)$, which again shows the participants' tendency to rely on the linguistic over the paralinguistic. The other half of the 'improved' responses $(20 \%)$, however, used the speaker's face to go from giving a wrong answer (at Level 1) to the right interpretation (at Level 2). What is worth noting is that two of the 'maximum score' participants and four of the ones showing 'improvement' seem to have used prosodic information (i.e. \was) to either confirm that the action described is a past action or change their mind about their interpretation. This again shows that 'maximum score' participants may have improved their interpretive strategies between Level 1 and Level 2 by using paralinguistic cues despite what the quantitative results seem to suggest.

Fig. 3 Sample 3 results: Before and after integrating qualitative data

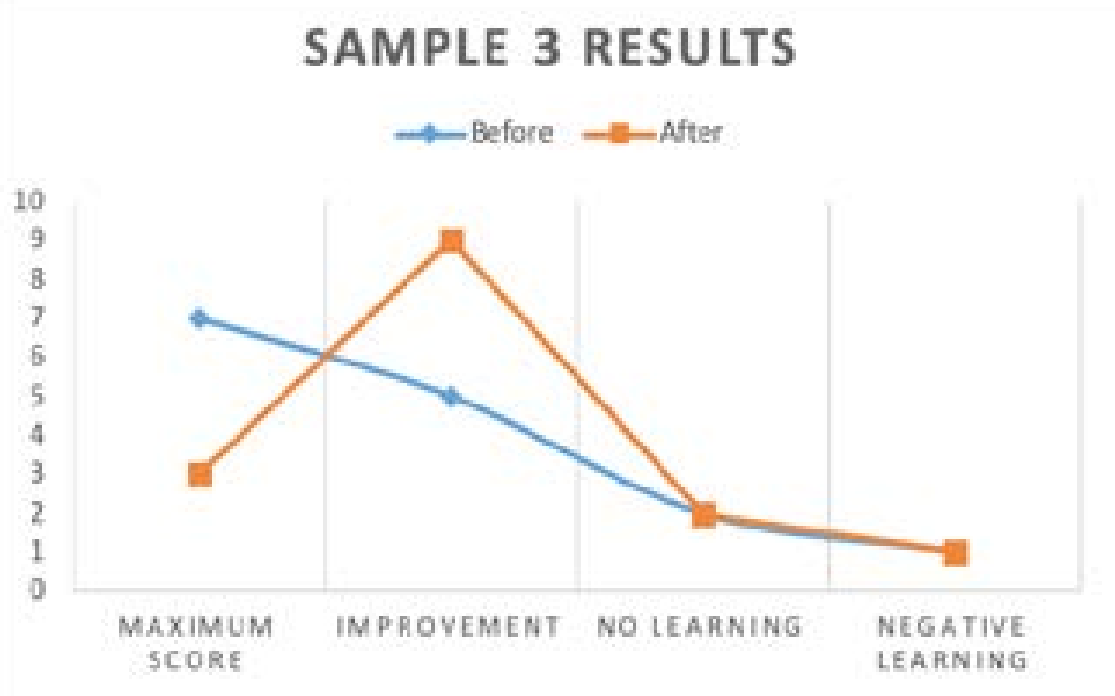

Fig. 3 below represents the difference between what sample 3 comprehension test results suggest and what the results tell us about the participants' performance once the qualitative data has been integrated. As illustrated by
Fig. 3, Sample 3 responses probably offer the most interesting results once convergence of the quantitative and qualitative findings has been done. Sample 3 results report $47 \%$ of participants with a 'maximum score', $33 \%$ of participants showing 'improvement', $13 \%$ of them showing 'no learning' and $7 \%$ of them showing 'negative learning'. Again, further investigation of what is behind the 'maximum score' responses reveal something else. Four of the seven 'maximum score' respondents had in fact improved between Level 1 and Level 2 with three of them having not only reached the intended interpretation but also formulated an intention-based interpretation: 'he thinks she's right - agrees with her' (participant 10). Five out of five participants showing 'improvement' have improved as a result of challenging their first interpretation and L1-established rule (e.g. 'he wasn't means 'No'): 'No he wasn't means 'Yes' to her question' (participant 15). As for the 'no learning' and 'negative learning' respondents, they did not challenge their first 'relevant enough' interpretation and decided to stick to L1-based assumptions: 'If I agree I should say 'yes" (participant 11), "he wasn't there means 'No" (participant 8). Making the qualitative and quantitative findings converge is particularly relevant to Sample 3, as from adding the 'maximum score' respondents who have improved their strategies between Level 1 and Level 2 to the rest of the participants showing 'improvement', we reach $60 \%$ of 'improvement' between Levels 1 and 2. Thus, so-called 'maximum score' participants may still have a way to go to get to the right interpretation, as he or she may further improve by reaching the intended interpretation at Level 2 . This is particularly true of Sample 3 where enquiring on the 'maximum score' responses allows us to almost double the number of participants showing improvement at Level 2.

\subsection{Discussion of results}

The objective of the experiment was to test whether exposure to prosodic pointing (at Level 2), as opposed to contrastive stress alone (at Level 1), could help Chinese learners of L2 English to arrive at the optimally relevant interpretation whether that is disagreement in a positive answer (Sample 1), agreement in a negative answer (Sample 3) or, more generally, extra 
pragmatic effects (Sample 2). After convergence of results, we observe a steady progression from Sample 1 to Sample 3 with $27 \%, 53 \%$ and $60 \%$ of improvement between Level 1 and Level 2 . This suggests a positive outcome of the study and that access to paralinguistic cues has helped the participants to fine-tune their interpretations. What convergence of results suggest is that the participants' interpretive performance and epistemic vigilance in the L2 may have developed even though comprehension test results do not show. This allows us to make a point: there is more to inferential comprehension than comprehension, and it may be best-suited to look at the 'evasive and thorny' area that listening comprehension is (PADILLA CRUZ 2013) from an L2 pragmatic competence perspective, and in doing so, to focus on L2 hearers as interpreters and on developing their ability to evaluate their own comprehension. Access to the processes, routes and detours involved in adjusting their interpretive strategies therefore is as important as the assessment of their comprehension.

The results show that exposure and improved access to the speaker's nonverbal contextual cues generates more comments and triggers intentionoriented interpretations. At Level 2, participants use descriptions such as 'he disagrees', 'he agrees', 'he thinks she's right', 'he wants to emphasise his questioning' to refer to the speaker's intentions. This suggests that exposure to prosodic pointing has helped in triggering ostensive-inferential processes. Although this does not apply to most participants at Level 2, these intentionoriented comments are not at all visible at Level 1. Thus, prosodic and gestural/facial cues play an important role in the participants' retrieval of the optimally relevant interpretations. Sample 2 results particularly show how attention to prosodic input can, together with facial expression and the past tense contribute to the participants' inference of speaker meaning. Attention to the past tense alone would not have been enough to infer that 'she failed in her attempt to lose weight'. Thus, what the results show is that exposure to prosodic pointing, as opposed to contrastive stress alone, was found to:

(1) Focus Chinese hearers of L2 English's attention on speaker's intentions, as illustrated above;

(2) Help listeners to develop more sophisticated, top-down interpretive strategies, and in particular
(3) Help learners to discriminate a 'yes' answer that means 'yes' from a 'yes' answer that means 'no', as the examples below demonstrate.

There is evidence of the participants going from stopping at the first most accessible or 'low-cost' interpretation (at Level 1) to one that involves them challenging L1-established assumptions and reaching the intended interpretation (at Level 2):

- No = he wasn't (Level 1) $->$ No, he wasn't = 'Yes' to her question (Level 2) From wrong to (close to) optimally relevant

- No, meaning 'yes' he was there' (Level 1) -> No, he wasn't no means 'Yes', he agrees (Level 2)

From wrong to optimally relevant

- Yes (Level 1) -> No - face = she wanted to but gave up (Level 2)

From wrong to optimally relevant

- 'Wasn't' (Level 1) -> He \was = meaning 'no' (Level 2)

From wrong to optimally relevant

- 'Yes, he wasn't' (Level 1) -> Yes = he thinks she's right - agrees with her (Level 2)

From relevant enough to optimally relevant

The above results show evidence of metapragmatic awareness, fundamental to the development of pragmatic competence and L2 hearers' alertness to intention-cueing paralinguistic features. The results suggest that the participants that have improved have developed cautious optimism through detection and appropriate use of ostensive behaviour.

The provided data therefore supports our argument that the pragmaticsprosody interface needs to be refined into a more inclusive phenomenon: prosodic pointing, if we are to look for ways of enhancing L2 listeners' 
interpretative strategies as part of developing their epistemic vigilance and pragmatic competence. It also supports the idea that for addressing the pragmatic problems identified in this paper (PADILLA CRUZ 2013), those are to be addressed together: learning to pay attention and being alert to paralinguistic contextual cues can help L2 learners read their interlocutor's mind. Reading the speaker's meaning is also a matter of reading the speaker's choices as to how he has communicated meaning, and paralinguistic cues are an important part of reading the speaker's choices.

As well as showing some positive effects of the intervention on L2 hearers' epistemic vigilance adjustment and fine-tuning, the qualitative results have further reflected the pragmatic problems characteristic of L2 learners, e.g. overreliance on linguistic input. Evidence of naïve optimism was also found; in other words, evidence of the participants believing one interpretation that yields some cognitive reward at a low cost (SPERBER 1994, PADILLA CRUZ 2013). For example, participants (8) and (14) noticed the visual input but have not used it in the interpretation:

- She was, yes - face expresses no (Level 2)

- Was means yes - face did not agree (Level 2)

The participants misused or did not use the noticed contextual cues as input for further inferential processes, which resulted in their failing to select and reach the intended interpretation. One suggested explanation based on the above data is the participants' reluctance to move away from established rules (i.e. 'was' means 'yes') which prevent them from challenging their initial interpretation even after noticing the cue that presumes of extra pragmatic effects (i.e. the speaker's face expressing 'no'). Interestingly, (8) and (14) also show that the use of the past tense ('was') is not a sufficient guarantee of the participants' understanding 'She was' as a 'no' answer. The results show that having more cues to play with in the interpretation process does not automatically translate into enhanced comprehension, at least not after one go. It may remain difficult for learners to recognise the input that will lead them to optimal relevance. It may also remain difficult for them to trust paralinguistic input particularly when it contradicts linguistic input. Therefore, one important facet of teaching inferential abilities in L2 listeners is to teach L2 interpreters to go from 'relevant enough' to optimally relevant and, in so doing, to recognise cues that presume of extra cognitive effects and justify the extra processing effort.

Thus, as well as shedding light on the role of prosodic pointing in adjusting learners' epistemic vigilance and thereby enhancing pragmatic competence, the qualitative part of the results have further pointed out some of the main problematics that Chinese L2 interpreters in particular are likely to face when exposed to prosodic pointing in situations of agreement and disagreement. We suggest that, in order to further address these problematics, instruction must focus on teaching L2 hearers to trust paralinguistic input. Reliance can mean dependence on and/or trust in something or someone. While previous studies have shed light on L2 learners' overreliance on linguistic input most probably in the sense of dependence, we suggest that we strive to teach them to rely on paralinguistic input, in the sense of trusting its worth. The outcomes of the study confirm that instruction has an important part to play in the development of L2 hearers' epistemic vigilance and pragmatic competence. The present study used implicit instruction. As a result, the participants did not always report on paralinguistic cues. Attention to visual input was not systematically reported in relation to successful inferences. Instruction that explicitly requires L2 learners to pay attention to and report on paralinguistic cues may hold a better chance of raising L2 learners' alertness to speaker's contextual cues and enabling them to read the speaker's intentions.

\section{Conclusions}

The aim of the paper was to test whether exposing Chinese learners of L2 English to, not only ostensive prosodic cues, i.e. contrastive stress, but also the facial modifications (i.e. frown), head movement (i.e. nod) and co-pointing gestures that prosody and particularly contrastive stress naturally and typically patterns with in English could enhance their pragmatic competence. We argued that together, prosody and gesture, can complement/contradict the grammatical or lexical realisation and, thus, contribute to pragmatic meaning. We have tested prosodic pointing as an ostensive multimodal phenomenon, and the results support our argument that the pragmatics-prosody interface needs expanding to include 
all paralinguistic features of communication. The study showed that relevance mechanisms and the ostensive-inferential domain can be explored in L2 pragmatics instruction to develop L2 hearers' inferential and interpretive competence.

The experiment involved exposing Chinese hearers of English to situations where misunderstanding arises. The study further pointed out the factors that Chinese L2 hearers typically take into account or overlook when processing input. This study is therefore in line with Padilla Cruz's call for 'activities that point out where the misunderstanding lies, the factors that misguide learners to wrong interpretations or those they do not pay attention to.' (2013, p. 130). In order to enhance their pragmatic competence, L2 hearers need to 'attune their epistemic vigilance to the peculiarities of the L2' (PADILLA CRUZ 2013, p. 130). The study has shown that attuning L2 hearer's epistemic vigilance to the peculiarities of the L2 can help in addressing the pragmatic problems faced by L2 learners, namely overreliance on linguistic input, lack of attention to paralinguistic cues, and difficulty carrying out top-down processing and reading their interlocutor's mind. The experiment has further shown that those pragmatic problems were particularly characteristic of Chinese learners of English and one main reason for them to be misguided and to fail to reach role in recovering speaker meaning, and paralinguistic cues play a central part in triggering and guiding inferential processes. L2 learners need to become aware of how prosodic and visual information typically 'enhances linguistic input, or distorts it, or replaces it, and sometimes even contradicts it.' (ROST 2016, p. 42). This, we argue, is a role for instruction.

In sum, the study contributes to the ongoing development of relevance theory as a theory of L2 listening instruction. We believe that further studies involving explicit instruction and repeated exposure to prosodic pointing would make a difference as to encourage L2 interpreters to systematically and fully exploit speaker's ostensive behaviours as guiding cues in the inferential path. This is expected to further fine-tune their epistemic vigilance to the peculiarities of English and, as a result, enhance their pragmatic competence as L2 hearers. the intended interpretation. In English, pragmatic mechanisms play a major

\section{References}

BLOOM, Paul. How children learn the meanings of words. Boston: MIT Press, 2001a. https:// doi.org/10.7551/mitpress/3577.001.0001

BLOOM, Paul. Précis of 'how children learn the meanings of words'. Behavioral and Brain Sciences, Cambridge, v. 24, n. 6, p. 1094-1103, 2001b. https://doi.org/10.1017/s0140525×01000139

CRESWELL, John W.; PLANO CLARK, Vicki L. Designing and Conduction mixed methods research. Thousand Oaks: Sage, 2006

GRICE, H. Paul. Logic and conversation. In: COLE, Peter; MORGAN, L. Jerry (ed.). Syntax and semantics 3: speech acts. New York: Academic Press, 1975. p. 41-58.

HALLIDAY, Michael A. K. Intonation and grammar in British English. The Hague: Mouton, 1967. https://doi.org/10.1515/9783111357447

HÖMKE, Paul; HOLLER, Judith; LEVINSON, Stephen C. Eye blinks are perceived as communicative signals in human face-to-face interaction. PLoS One, San Francisco, v. 13, n. 12, p. e0208030 2018. https://doi.org/10.1371/journal.pone.0208030

IFANTIDOU, Elly. Relevance theory, epistemic vigilance and pragmatic competence. In: PADILLA CRUZ, Manuel. (ed.). Relevance theory: recent developments, current challenges and future directions. Amsterdam: John Benjamins, 2016. p. 193-238. https://doi.org/10.1075/pbns.268.08ifa

JODLOWIEC, Maria. The role of relevance theory in SLA studies. In: PÜTZ, Martin; SICOLA Laura (ed.). Cognitive processing in second language acquisition. Amsterdam: John Benjamins, 2010. p. 49-66. https://doi.org/10.1075/celcr.13.06jod

MACNAMARA, John. The cognitive basis of language learning in infants. Psychological Review, Washington, v. 79, n. 1, p. 1-13, 1972. https://doi.org/10.1037/ho031901

MADELLA, Pauline; WHARTON, Tim J. Prosodic and gestural pointing: multi-modality in action. In: IFANTIDOU, Elly; DE SAUSSURE, Louis; WHARTON, Tim (ed.). Beyond meaning. (In press).

MUNDY, Peter; NEWELL, Lisa. Attention, joint attention, and social cognition. Current Directions in Psychological Science, New York, v. 16, n. 5, p. 269-274, 2007. https://doi.org/10.1111/j.14678721.2007.00518.x

PADILLA CRUZ, Manuel. Metapsychological awareness of comprehension and epistemic vigilance of L2 communication in interlanguage pragmatic development. Journal of Pragmatics, Amsterdam, v. 59, part A, p. 117-135, 2013. https://doi.org/10.1016/j.pragma.2013.09.005

Letrônica | Porto Alegre, v. 12, n. 3, out.-dez 2019: e34157 
PADILLA CRUZ, Manuel (ed.). Relevance theory: recent developments, current challenges and future directions. Amsterdam: John Benjamins, 2016.

RIESCO BERNIER, Silvia; ROMERO-TRILLO, Jesús. The acoustics of "newness" and its pragmatic implications in classroom discourse. Journal of Pragmatics, Amsterdam, v. 40, n. 6, p. 1103-1116, 2008. https://doi.org/10.1016/i.pragma.2008.02.002

ROMERO-TRILLO, Jesús (ed.). Pragmatics, prosody and English Language teaching. Dordrecht: Springer, 2012.

ROMERO-TRILLO, Jesús. Prosodic modelling and position analysis of pragmatic markers in English conversation. Corpus Linguistics and Linguistic Theory, v. 14, n. 1, p. 169-195, 2015. https://doi.org/10.1515/cllt-2014-0026

ROMERO-TRILLO, Jesús. Prosodic pragmatics and feedback in intercultural communication. Journal of Pragmatics, Amsterdam, v. 151, p. 91-102, 2019. https://doi.org/10.1016/j. pragma.2019.02.018

ROMERO-TRILLO, Jesús. The pragmatic fossilization of discourse markers in non-native speakers of English. Journal of Pragmatics, Amsterdam, v. 34, n. 6, p. 769-784, 2002. https:// doi.org/10.1016/s0378-2166(02)00022-x

ROST, Michael. Teaching and researching listening. New York: Rouledge, 2016. https://doi. org/10.4324/9781315732862

SCOTT, Kate. Ostension, expectations and non-encoded meaning presentation. In: BEYOND MEANING. Athens: National and Kapodistrian University of Athens, 2017. Oral communication.

SPERBER, Dan. Understanding verbal understanding. In: KHALFA, Jean (ed.). What is intelligence? Cambridge: Cambridge University, 1994. p. 179-198.

SPERBER, Dan et al. Epistemic vigilance. Mind and Language, Oxford, v. 25, n. 4, p. 359-393, 2010. https://doi.org/10.1111/j.1468-0017.2010.01394.X

SPERBER, Dan; WILSON, Deirdre. Relevance: communication and cognition. Oxford, Blackwell, 1986.

SPERBER, Dan; WILSON, Deirdre. Relevance theory. In: HORN, Laurence R.; WARD, Gregory (ed.). The handbook of pragmatics. Oxford: Blackwell, 2004. p. 607-632.

SPERBER, Dan; WILSON, Deirdre. Remarks on relevance theory and the social sciences. Multilingua, Berlin, v. 16, n. 2-3, p. 145-51, 1997. https://doi.org/10.1515/mult.1997.16.2-3.145
WHARTON, Tim, J. Meaning and showing: Gricean intentions and relevance theoretic intentions. Intercultural Pragmatics, [s. l.], v. 5, n. 2, p. 131-152, 2008. https://doi.org/10.1515/ip.2008.008

WHARTON, Tim J. Paralanguage. In: BARRON, Anne; STEEN, Gerard; YUEGUO, Gu (ed.). The Routledge handbook of pragmatics. London: Routledge, 2016. p. 69-75. https://doi.org/10.1515/ ip-2017-0032

WHARTON, Tim J. What words mean is a matter of what people mean by them. Linguagem em (Dis)curso, Tubarão, v. 14, n. 3, p. 473-488, 2014. https://doi.org/10.1590/1982-4017-140302-0214

WILSON, Deirdre; SPERBER, Dan. Pragmatics, modularity and mind-reading. Mind and Language, Oxford, v. 17, n. 1, p. 3-23, 2002. https://doi.org/10.1111/1468-0017.00186

ZUFFEREY, Sandrine. Acquiring pragmatics: social and cognitive perspectives. New York: Routledge, 2015. https://doi.org/10.4324/9781315747958

\section{Appendix 1}

Full dialogue:

Speaker $1(\mathrm{~S} 1)$ and Speaker 2 (S2):

\section{S1 Shame $\backslash$ Karl wasn't at the party |}

\section{S2 He \was at the party | Didn't you / see him? |}

S1 $\quad$ Karl $\backslash$ Smith? |

S2 \No | tall Karl | Karl \Oliver | \/ I saw him | didn't / you? |

S1 I saw his $\backslash$ brother | but I didn't think $\backslash$ he was there |

S2 His brother \wasn't there $\mid$ His $\backslash$ sister was

S1 Yes, I $\backslash$ spoke to her | Is she trying to lose / weight|

S2 She $\backslash$ was

S1 \/ Jack wasn't there, then?

S2 He $\backslash$ wasn't $\mid \backslash$ no $\mid$ but Jack isn't $\backslash$ Karl's brother $\mid$ He's $\backslash$ Tom's brother | 


\section{Appendix 2}

\begin{tabular}{|c|c|}
\hline $\begin{array}{l}\text { PARTICIPANTS' QUALITATIVE RESPONSES } \\
\text { AT LEVEL } 1\end{array}$ & $\begin{array}{l}\text { PARTICIPANTS' QUALITATIVE RESPONSES } \\
\text { AT LEVEL } 2\end{array}$ \\
\hline 1. A. Man surprised that he was & $\begin{array}{l}\text { 1. A. Questioning, surprised, he wants to } \\
\text { emphasise his questioning }\end{array}$ \\
\hline B. She was trying. For now, it's no & B. Face - not now, before \\
\hline $\begin{array}{l}\text { C. Answer is no but answer to question is } \\
\text { yes, (he didn't) }\end{array}$ & C. No, agrees with her \\
\hline 2. A. He wasn't & $\begin{array}{l}\text { 2. A. He wasn't - suspicious face. Didn't you } \\
\text { see him? }\end{array}$ \\
\hline B. Yes & B. No - face $=$ it's a secret \\
\hline C. Wasn't = no & C. Yes, he wasn't \\
\hline 3. A. Was & 3. A. No - face \\
\hline B. She was & B. She was -> face shows she didn't succeed \\
\hline C. Yes, he wasn't & C. Yes, he wasn't \\
\hline
\end{tabular}

\begin{tabular}{|c|c|}
\hline $\begin{array}{l}\text { PARTICIPANTS' QUALITATIVE RESPONSES } \\
\text { AT LEVEL } 1\end{array}$ & $\begin{array}{l}\text { PARTICIPANTS' QUALITATIVE RESPONSES } \\
\text { AT LEVEL } 2\end{array}$ \\
\hline 4. A. Yes & $\begin{array}{l}\text { 4. A. Yes - Surprised she didn't see him - face } \\
\text { looks negative }\end{array}$ \\
\hline B. Was & B. She was \\
\hline C. Yes, he wasn't there & C. Yes, he wasn't \\
\hline $\begin{array}{l}\text { 5. A. Wasn't } \\
\text { B. Before, not now } \\
\text { C. Doesn't know }\end{array}$ & $\begin{array}{l}\text { 5. A. He was at the party } \\
\text { B. She was, before - no meaning } \\
\text { C. No }\end{array}$ \\
\hline $\begin{array}{l}\text { 6. A. Was } \\
\text { B. She was = yes } \\
\text { C. No - he says no }\end{array}$ & $\begin{array}{l}\text { 6. A. Wasn't (face=no) } \\
\text { B. She was } \\
\text { C. Yes, he wasn't }\end{array}$ \\
\hline $\begin{array}{l}\text { 7. A. No } \\
\text { B. Yes } \\
\text { C. He wasn't, no = no }\end{array}$ & $\begin{array}{l}\text { 7. A. No } \\
\text { B. She was - tried but did not succeed } \\
\text { C. No = he agrees with her }\end{array}$ \\
\hline $\begin{array}{l}\text { 8. A. Was } \\
\text { B. She was } \\
\text { C. He was - confused with previous ques- } \\
\text { tion }\end{array}$ & $\begin{array}{l}\text { 8. A. shake of head - (Yes) he was } \\
\text { B. She was, yes - face expresses no } \\
\text { C. He wasn't there = no }\end{array}$ \\
\hline 9. A. He not $->$ he was & $\begin{array}{l}\text { 9. A. He was. Didn't you see him? Looks sur- } \\
\text { prised because the woman didn't see him }\end{array}$ \\
\hline B. Yes & B. She was - before, not now \\
\hline C. Two not means yes & C. Jay wasn't $->$ no, he wasn't $->$ Yes, he wasn't \\
\hline $\begin{array}{l}\text { 10. A. No } \\
\text { B. She was } \\
\text { C. Same as question -> yes, he wasn't }\end{array}$ & $\begin{array}{l}\text { 10. A. No - man shakes head } \\
\text { B. Yes } \\
\text { C. Yes = he thinks she's right - agrees } \\
\text { with her }\end{array}$ \\
\hline
\end{tabular}




\begin{tabular}{|c|c|}
\hline $\begin{array}{l}\text { PARTICIPANTS' QUALITATIVE RESPONSES } \\
\text { AT LEVEL } 1\end{array}$ & $\begin{array}{l}\text { PARTICIPANTS' QUALITATIVE RESPONSES } \\
\text { AT LEVEL } 2\end{array}$ \\
\hline 11. A. Yes & $\begin{array}{l}\text { 11. A. He was - surprised because she thou- } \\
\text { ght he wasn't }\end{array}$ \\
\hline B. She was & B. She was - did in the past $=$ no \\
\hline C. Yes, he wasn't & $\begin{array}{l}\text { C. No he wasn't = no - if I agree I should } \\
\text { say yes }\end{array}$ \\
\hline 12. A. Wasn't & 12. A. He was - meaning no \\
\hline B. Not now & B. She was \\
\hline C. Yes, he wasn't there & C. Yes, agrees \\
\hline 13. A. Yes & $\begin{array}{l}\text { 13. A. She: he wasn't; he: he was - shakes } \\
\text { head }\end{array}$ \\
\hline B. Yes & B. No - face $=$ she wanted to but gave up \\
\hline C. Wasn't - no $=$ yes & C. Yes, he wasn't \\
\hline 14. A. Was & 14. A. Yes, he was - but shakes head \\
\hline B. She was - past tense in question & B. Was means yes - face didn't agree \\
\hline C. No meaning 'yes' he was there & C. No he wasn't no means Yes, he agrees \\
\hline 15. A. Was & 15. A. No \\
\hline B. Probably still, not sure & B. She \was - no \\
\hline C. No = he wasn't & $\begin{array}{l}\text { C. No he wasn't = Yes to her question - } \\
\text { same answers }\end{array}$ \\
\hline
\end{tabular}

